\title{
Analysis for Individual Knowledge Management of University Teacher Changjiao Qiao ${ }^{1, a}$, Yonggui $\mathrm{Mu}^{2, \mathrm{~b}}$, Jingbo $\mathrm{Ai}^{3, \mathrm{c}}$ \\ ${ }^{1,2}$ Military education training department Aviation University of Air Force 130022, Changchun, Jilin Province, China \\ ${ }^{3}$ No.103 Middle School of Changchun Yatai Street, Changchun, Jilin Province, China 130041 \\ a Email Address: 1306383988@qq.com, ${ }^{\mathrm{b}}$ Email Address: myg123789@sina.com, ${ }^{\mathrm{c} E m a i l}$ Address: 2675428821@qq.com
}

Keywords: University, Teacher, Individual knowledge management

\begin{abstract}
As a new manage mode and method, knowledge management is applied to educational areas. Under the current training systems for university teachers, efficient management of teacher's individual knowledge is restricted by two elements: First, consciousness absence for knowledge management, and seriously monopolistic consciousness of individual knowledge. Second, absence of platforms or conditions for equal communications and knowledge sharing. The efficient individual management of university teacher could be realized by common efforts from university organization systems and teacher himself.
\end{abstract}

Teacher's individual knowledge management refers to the systematic procedures which rely on the power for save and use of team knowledge and wisdoms, which spur growth of individual professions, and which promote development of professions and qualities from the teach-area which combined with information technology. ${ }^{[1]}$ Individual knowledge management is benefit to promote individual working abilities, promote development of professions and qualities, and promote competitive power for organizations. As a new manage mode and method, individual knowledge management is applied to university educational areas in country. The main achievements are focused on manage tasks and research of technology which in the manage views of individual knowledge. For example, Zhang Xufang etc. from Beijing Jiaotong University, have built a concept mode for teacher knowledge management and performance evaluation which rely on the individual knowledge resources. ${ }^{[2]}$ But this mode has a great limitations for not to observe systematically for teacher's knowledge management. Therefore, I think it has an important realistic meanings which start from the training system for faculty, explore teacher's individual knowledge management issues and promote university teachers knowledge structure,and keep vigors and vitalities of university education.

\section{First, the individual knowledge management focuses on current university teacher training system.}

Currently, the university teacher training is divided into two levels. And these two levels are important ways for organize and manage the rich individual knowledge to management of teachers. First, induct training and class teaching. By working training for one week and teach contents for one or two weeks of teach preparation and class teaching to reinforce their practical knowledge and 
skills. New teachers should manage their individual knowledge systematically by means of organization on this stage, and to training personality, teaching abilities and qualities. Second is job training. On this stage, aims are to rich and perform self educational structures of teachers, to update knowledge, promote qualities and ensure the quality of education.

Consciousness absence for knowledge management, and seriously monopolistic consciousness of individual knowledge.

This is mainly reflected through the process of teacher's knowledge management. Currently, most of university teachers are still relatively vague to the knowledge management, as Hargreaves said, "Teachers always overlook their own professional knowledge, This result to they can't share and apply these knowledge. And they also don't know absence of knowledge of their own; this could not find the needs and create new knowledge." It's a complex social distribution in school-house. No one teacher could know all these hidden overall expertise totally." ${ }^{[3]}$ Personal independent experiences and professional knowledge are accustomed to teachers own resources and capital to compete, often stick to their own business and independent kingdom who do not to cooperate with others. This result the impediments of teachers, and limiting the interaction between teachers and multilateral support or experience on the dependence with long-term isolation and insulation

Even provide the opportunities for them, it's always tending to conservative and unnatural for knowledge sharing and applying. Teachers always doubt: Why should I share these resources to threaten ourselves if the individual knowledge is valuable? If my job is to create knowledge, why do I have to instead your knowledge of mine? On the one hand, you would lose the authority and monopoly states in this field once you open your experiences. On the other hand, there is no appropriate system for university knowledge sharing. So, teachers do not want to share their own knowledge especially practical knowledge with others.

II. Absence of platforms or conditions for equal communications and knowledge sharing.

This is mainly reflected in the input processing of the organization for the teachers. The methods for uniform requirement, executive orders etc. in university which prominent in highly concentrated, make hierarchical management errors in university, are strictly on the basis of the Headmaster-Administrative authority—Director of the staff room-Leader of teach—Teacher for teach management. The dialogues for management of teachers are lacked of equality context, and result their limitation of inner valuation and persuasion, and hampering their expertise in decision-making autonomy in this pyramid-shaped unidirectional, compulsory level management.

\section{Second, methods for individual knowledge management of university teacher}

According to the theory of management, and in the current system of university, the individual knowledge management for teachers could complete in two ways of organize management system and teacher themselves.

I. Organization and management of knowledge management for individual teachers.

One is need to building knowledge platform. Knowledge communication platform of university is used to collect, mining the explicit and tacit knowledge of teachers. It could be not only 
traditional forms like teaching groups, seminars, etc., but also website blog establishment for knowledge communicating. Traditional forms of professional communication for teachers who face-to-face, is conductive to the formation of professional community, both from issues of interest to participate in education and teaching, to participate in the teaching situation of dialogue to promote knowledge sharing and communicating. The website blog is composed by short update usually articles, and which can be recording, publishing, reflection, sharing, and creating etc. And its characteristics are zero technology, low cost, strong sharing, and accumulation such functions. On the basis of maintaining the traditional forms of communication, the university teach management systems are also use blogs as a communicating tool, which make some private places for teachers on university websites, this can enhance communicating and cooperating between teachers, and promote sharing, communicating and creating of professional knowledge.

Two is to establish the knowledge Base. Knowledge Base is a structuring, easy-handling, easy-using, comprehensive and organized knowledge cluster, for field to solve problems, knowledge representations, which using some knowledge representation in computer memory store, organize, manage, and use a collection of these knowledge including university teacher lesson plans, papers teaching materials, learning manual, expert lectures, academic reports, journals, audio and video education information, electronic presentation, teaching experiences, etc. Through the classification and coding of knowledge pieces, and sort into a general knowledgebase, knowledge communicating are easy to use. The aim of getting the methods on structure of the knowledgebase of all teachers is to support their teach researching for reference who need them. Nowadays, knowledge updating is shorter and quicker. Therefore, the contents of knowledgebase are constantly updated and enriched.

Three is to draw the knowledge map of university. Knowledge map is a kind of knowledge navigates system. It mainly display the important dynamic link between knowledge storage, and can help teachers to get knowledge according to map. It's an important manage tool for build and apply the university knowledgebase. The knowledge map is a network of communicating for inner teachers, outside professors and scholars, which can search the knowledge they need, and share their knowledge by consulting, special guidance, exchange visits etc. The knowledge map can help teacher to make full use, and prevent repeat productions of knowledge, save time for sorting and achieving information, and can help to find individual knowledge islands, building a two-way communicating sharing. It can also help teachers to get knowledge which they need quickly, and help them to solve problems through teaching and researching.

II. Teachers of individual knowledge management

First, establish individual knowledge management awareness. Whether teachers have individual knowledge awareness would determine their ability to get individual professional development of active developing and exploring, but also determine level of conscious whether they use statistics management and use, creating. Teachers should incorporate knowledge management and learning in their daily work and study, keep and to systematize knowledge of life, and new knowledge into personal knowledge system. Only individual knowledge management integrated into teacher's life, to persevere, become an important method of their professional development and improvement. 
Second, establish a personal electronic storage system. University teachers could sort material information with computer, store them in time and in classification, and build a personal knowledge management system for easy finding and using. And also teachers could use training, self-studying and reflective learning to accumulate knowledge and improve their abilities of learning and updating.

Third, learn to use various management methods. Teachers should be good at get tacit knowledge, often to reflect and summary teaching, and manage the complex knowledge automatically. At the same time, teachers should enhance their abilities of web search, storage, management and use, and not only to use network for information searching and finding, but also to use software for clashing, filing, storing and extracting. Teachers can use E-mails and RBS with others to communicate and save knowledge resources.

\section{References}

[1]Sai Mingming Analysis of Mask and Application Skills for Teachers Knowledge Management [J].University,2011 (5):66-67

[2]Zhang Xufang,Zhang Junwen Research and Design of Knowledge Management System for University Teachers[J].Teach of researching,2009 (15):17-18

[3]Gan Yongcheng Learning Personal Knowledge Management under Environment [[J].Chinese Audio Visual Education,2003 (6) ):20-24.

[4] Yi Lingfeng Zhu Jingqi Knowledge Management Fudan University Press[M]. 2008.

[5] Gu Jifa Knowledge Management Science Press (2009.03) Beijing 